\title{
Does additional information provided by cone beam computed tomography (CBCT) and a consequent modification of surgical technique reduce the possibility of inferior alveolar nerve injury? A pilot study
}

SADJ March 2019, Vol. 74 No. 2 p62 - p66

M Mabongo', MD Thekiso²

\section{ABSTRACT}

Objectives

To compare the incidence of inferior alveolar nerve injury after lower third molar extraction between two groups who had undergone differing preoperative diagnostic radiological assessments.

\section{Material and methods}

A pilot study was conducted comparing potential surgical complications between two groups before surgical removal of lower impacted third molars. The patients $(n=93)$ were divided into two groups: panoramic $x$-ray and Cone-beam computed tomography group $(n=38)$ and the panoramic $x$-ray group $(n=55)$. Post-operative complications in each group were recorded a week after surgery. Multivariate logistic regression was used to determine the association between the incidence of nerve injury and other variables.

\section{Results}

The inferior alveolar nerve was exposed during the procedure in only six patients $(6.45 \%)$ and thirteen patients (13.98\%) had transient paraesthesia a week post-surgical extraction. In twelve patients $(92.30 \%)$ sensation fully recovered within the first month after the procedure with one patient $(1,08 \%)$ having paraesthesia after six months post-extraction.

\footnotetext{
Author affiliations:

1. Mzubanzi Mabongo: BDent, BDS, MChD (MFOS), Head of Clinical Unit, Department of Maxillofacial and Oral Surgery, School of Oral Health Sciences, Faculty of Health Sciences, University of the Witwatersrand, Johannesburg, South Africa.

2. Maphefo D. Thekiso: BChD, MDent (Community Dentistry), Specialist, Department of Community Dentistry, School of Oral Health Sciences, Faculty of Health Sciences, University of the Witwatersrand, Johannesburg, South Africa.

Corresponding author: Mzubanzi Mabongo

Department of Maxillofacial and Oral Surgery, School of Oral Health Sciences, Faculty of Health Sciences, University of the Witwatersrand, 7 York Road, Parktown 2193, Johannesburg, Tel: +27 (0)11 7172243. Email: mzubanzi.mabongo@wits.ac.za
}

\author{
ACRONYMS \\ CBCT: $\quad$ Cone Beam Computed Tomography \\ IAN: Inferior Alveolar Nerve \\ L3M: Lower Third Molars \\ PGC: $\quad$ Pell and Gregory Classification
}

\section{Conclusions}

Additional information gathered from Cone-beam computed tomography and precautionary measures taken during surgery did not reduce the incidence of IAN injury.

\section{Keywords}

Cone-beam computed tomography, paraesthesia, lower third molar, inferior alveolar nerve.

\section{INTRODUCTION}

Surgical removal of impacted lower third molars (L3Ms) is one of the most commonly performed procedures in oral surgery. The indications for the procedure include the following: recurrent pericoronitis, interference with reduction of fractures, preparing for orthognathic surgery, carious lesions, and pathology associated with impacted L3Ms. The complications of this procedure include damage to the inferior alveolar nerve (IAN) with subsequent neurosensory impairment of the lower lip and chin. ${ }^{1}$

A panoramic radiograph is generally mandatory before surgical removal of L3Ms. Various signs have been described on the panoramic image that may indicate a close proximity of the L3M roots to the inferior alveolar canal. ${ }^{2-4} \mathrm{~A}$ study by Hasengwa et al. ${ }^{5}$ however, suggests that a panoramic radiograph alone does not provide sufficient information to confirm the relationship between an impacted tooth and the mandibular canal. These authors recommend that additional radiography be used, namely cone beam computed tomography (CBCT), the gold standard for accurate evaluation of these relationships. ${ }^{6}$ 
The main advantage of CBCT scans is that they provide three-dimensional views with lower radiation exposure. However, they are very costly. ${ }^{7}$

Apart from proximity issues, other risk factors associated with the surgical procedure that have been cited in the literature include inadequate experience of the surgeon, elderly patients with fully developed roots, deep impaction, ${ }^{8}$ and intraoperative exposure of the IAN. ${ }^{9}$

A few studies have reported an association between the Pell and Gregory classification (PGC) and the likelihood of an IAN injury. ${ }^{8}$ Several studies suggest that the use of CBCT scans in patients with radiographic signs of close proximity of the root of an impacted wisdom tooth to the mandibular canal may be instrumental in reducing the risk of an IAN injury. ${ }^{10,11}$ However, a study by Sanmarti-Garcia ${ }^{6}$ reported that this does not necessarily apply.

Hence there are conflicting reports in the dental literature on whether the preoperative use of CBCT aids the surgeon in reducing the prevalence or severity of an IAN injury. ${ }^{6,10,11}$ The aim of this study was to determine whether having a preoperative CBCT scan had any influence on the incidence and evaluation of an IAN injury caused during L3M extraction. A comparison was made of two groups of patients who had had differing radiological examinations but showed similar radiologic signs indicating proximity between tooth roots of the L3M and the mandibular canal.

The study firstly determined the incidence of IAN injuries in patients treated at the Maxillofacial and Oral Surgery Department. The objective then was to assess the utility of CBCT in providing preoperative information which could prevent the occurrence, or decrease the severity, of an IAN injury that may occur during an extraction of a L3M that is seen on a panelipse to be in close relation to the mandibular canal.

\section{MATERIALS AND METHODS}

\section{Study Population}

A pilot study was conducted from January 2014 to December 2014 on patients presenting for surgical extraction of symptomatic impacted L3M's at the Maxillofacial and Oral Surgery Department at the University of the Witwatersrand. All eligible participants were aged 18 years or older and had panoramic radiographs which depicted signs that suggested close proximity between the tooth roots and the mandibular canal.

Patients presenting with any pathology (granuloma, cysts or tumours) associated with the root of an impacted L3M and with L3M mandibular fractures were excluded. Informed consent was obtained from all volunteers, and the Human Research Ethics Committee of the University of the Witwatersrand (M130915) granted ethical permission for the study.
Patients were randomly allocated to one of the following two groups: a control group (panelipse only) or an intervention group (panelipse and $\mathrm{CBCT}$ ). Sealed envelopes containing cards with either "panelipse only" or "panelipse and CBCT" were placed in a box. Each patient was requested to pick up an envelope that would allocate him/her to a group.

\section{Data collection}

A data collection sheet was used to record the required information, which was categorized into preoperative, operative, and postoperative data. Recorded preoperatively were data on: gender, age, tooth number, depth and orientation of the impacted L3M. Two calibrated radiologists assessed the pan and the $\mathrm{CBCT}$ scans.

The inter-examiner agreement was assessed using the Kappa statistic, with an overall value of 0.7-0. 8 for panoramic $x$-ray films and 0.8 - 0.9 for the CBCT scan. The depth and orientation of the impactions were recorded using PGC and Winters' classification.

Intraoperative data that was recorded included the surgical procedure performed on each tooth, any complications, the experience of the surgeon in years, and exposure of the IAN.

Additional information acquired from the CBCT was used in the endeavour to prevent injury to the IAN. The surgical procedures were recorded as follows: intra-alveolar dental extraction (extraction); whether or not a flap was raised $(F)$; elevation of the tooth $(E)$; bone removal (B); and tooth sectioning / odontectomy (D). At the postoperative stage recorded data included neurosensory disturbance, infections, alveolitis, and any other complications.

All patients underwent surgical removal of the tooth, performed using a buccal approach, under local anaesthesia by an oral and maxillofacial surgeon and registrars (residents). In patients with the inferior alveolar canal located on the buccal side to the L3M, the surgeon luxated the tooth in a buccal direction, thus rotating the apex in a lingual direction.

When the inferior alveolar canal was located lingually to the L3M the surgeon luxated the tooth in a lingual direction, thereby rotating the tooth in the direction opposite to the inferior alveolar canal. ${ }^{12}$

Another surgeon who was blinded to both the preoperative and intraoperative data of the control and intervention groups, reviewed all patients. The patients had a postoperative review appointment a week after the surgery to assess any postoperative complications.

Neurosensory disturbances of the lip and the chin were first assessed through self-reported outcomes. Subjective and objective assessments were performed with the light touch test (with von Frey fibres) and a two-point discrimination threshold in patients complaining of neurosensory disturbance. ${ }^{13}$ 


\section{Statistical analysis}

The collected data were statistically analyzed using the SPSS version 19 for Windows (IBM SPSS, Chicago, IL, USA). Descriptive statistics were used to summarize all measurements. The association be tween categorical variables was tested with Fisher's exact test. A Mann-Whitney nonparametric test was used to compare ages between the two groups.

A P-value $<0.05$ was considered statistically significant. Multivariate Logistic regression was used to determine the association between nerve injury and other variables. The odds ratio was used to determine the strength of the association.

\section{RESULTS}

The study involved 93 patients, 52 (55.91\%) women and $41(44.09 \%)$ men (Table 1$)$. The age range of the patients was between 23 and 32 years with a median of 27 years. Thirty-eight patients (40.86\%) had both a panelipse and a CBCT scan taken, while 55 (59.14\%) had only a panelipse taken. The majority of patients had level $1 \mathrm{~A}$ and $2 \mathrm{~A}$ impactions, only three having $2 \mathrm{C}$ impactions, according to the PGC classification.

The distribution of patients in relation to the radiographic signs of root proximity to the inferior alveolar canal is shown in Table 1. Twenty-eight patients $(30 \%)$ were treated by an oral and maxillofacial surgeon, while 65 (70) were treated by residents. Thirteen patients (13.98\%) had transient paraesthesia a week after surgical extraction, eight in the intervention group (21.05\%) and five in the control group $(9.09 \%)$. Eleven were treated by residents. Twelve patients recovered from this paraesthesia within the first month after the procedure. One patient $(1.08 \%)$ continued to have paraesthesia after six months.

Fisher's exact test (Table 2) showed a statistically significant association between an IAN injury and the depth of the impaction $(p=0.036)$, the surgical procedure $(p=0.007)$ and the nerve exposure $(p=0.034)$.

Even though only three patients were affected, the bivariate and multivariate logistic models showed that nerve exposure (OR: 7.7; 95\% C.I: $1.36-43.46$; $p=$ 0.021); (OR 17.30; 95\% C.I: 2.10-142.50; $p=0.008$ ) and PGC classification (2C) (OR: 24 ; $95 \% \mathrm{Cl} 1.46-394$; $\mathrm{p}=0.026) ;$ OR: $40.41 ; 95 \% \mathrm{Cl} 1.71-951.85 ; \mathrm{p}=0.22)$ had significant associations with IAN injury. (Table 3).

\section{DISCUSSION}

Inferior alveolar nerve injury is a serious complication of the surgical removal of an impacted L3M. The incidence of IAN injury ranges from $0.5 \%$ to $17 \%,{ }^{14}$ with a $14 \%$ prevalence. ${ }^{6}$ Permanent injury has been reported as $0.12 \%$ of cases. ${ }^{13}$ An IAN injury may be perceived as tingling, numbness, or as a burning, painful sensation affecting the lower lip, chin, and teeth or labial gingiva. ${ }^{4} \mathrm{~A}$ study by Ghaeminia et al. reported a $17 \%$ incidence of transient injury.

\begin{tabular}{|c|c|}
\hline Characteristics & Frequency (\%) \\
\hline \multicolumn{2}{|l|}{ Gender } \\
\hline Male & $41(44.09)$ \\
\hline Female & $52(55.91)$ \\
\hline Age Median (IQR) & $27(23-32)$ \\
\hline \multicolumn{2}{|l|}{ Sign } \\
\hline IWL & $46(49.46)$ \\
\hline $\mathrm{RR}$ & $28(30.11)$ \\
\hline DR & $9(9.68)$ \\
\hline DC & $4(4.30)$ \\
\hline NC & $6(6.45)$ \\
\hline \multicolumn{2}{|l|}{ СВСТ } \\
\hline No & $38(40.86)$ \\
\hline Yes & $55(59.14)$ \\
\hline \multicolumn{2}{|c|}{ Winters Classification } \\
\hline MA & $39(41.94)$ \\
\hline v & 30 (32.26) \\
\hline H & $24(25.81)$ \\
\hline \multicolumn{2}{|l|}{ Pell Gregory } \\
\hline $1 \mathrm{~A}$ & $26(27.96)$ \\
\hline $2 A$ & $34(36.56)$ \\
\hline 1B & $17(18.28)$ \\
\hline $2 B$ & $11(11.83)$ \\
\hline $2 \mathrm{C}$ & $3(3.23)$ \\
\hline $3 \mathrm{~A}$ & $2(2.15)$ \\
\hline \multicolumn{2}{|l|}{ Tooth } \\
\hline Right Side & 45 (48.39) \\
\hline Left Side & $48(51.61)$ \\
\hline \multicolumn{2}{|l|}{ Complications } \\
\hline None & 73 (78.49) \\
\hline Pain & $1(1.08)$ \\
\hline IAN & $13(13.98)$ \\
\hline Septic Socket & $4(4.30)$ \\
\hline Dry Socket & $2(2.15)$ \\
\hline \multicolumn{2}{|l|}{ Work Experience } \\
\hline $5-15$ years & 65 (69.89) \\
\hline $15+$ & $28(30.11)$ \\
\hline \multicolumn{2}{|l|}{ Surgical Procedure } \\
\hline Extraction & $9(9.68)$ \\
\hline FE & $28(30.11)$ \\
\hline FBE & $2(2.15)$ \\
\hline FBD & $54(58.06)$ \\
\hline \multicolumn{2}{|l|}{ Nerve Exposure } \\
\hline No & $87(93.55)$ \\
\hline Yes & $6(6.45)$ \\
\hline \multicolumn{2}{|l|}{ Acronyms } \\
\hline \multicolumn{2}{|c|}{$\begin{array}{l}\text { IQR }=\text { interquantile range } \\
\text { IWL }=\text { Interruption of white line } \\
\mathrm{RR}=\text { Root radioluscency } \\
\mathrm{DR}=\text { Diversion of the root } \\
\mathrm{DC}=\text { diversion of the cana } \\
\mathrm{NC}=\text { narrowing of the canal } \\
\mathrm{MA}=\text { Mesio-angular impaction } \\
\mathrm{V}=\text { Vertical impaction } \\
\mathrm{H}=\text { Horizontal impaction } \\
\mathrm{FE}=\text { flap raised and elevation of the tooth } \\
\mathrm{FBE}=\text { Flap raised, bone removal and elevation of the tooth } \\
\mathrm{FBD}=\text { Flap raised, bone removal and dentectomy } \\
\\
\text { (sectioning of the tooth). }\end{array}$} \\
\hline
\end{tabular}




\begin{tabular}{|c|c|c|c|}
\hline Factors & $\begin{array}{l}\text { IAN } \\
(n=13)\end{array}$ & $\begin{array}{l}\text { Other } \\
\text { Complications } \\
(\mathrm{n}=80)\end{array}$ & p-value \\
\hline \multicolumn{4}{|l|}{ Gender } \\
\hline Male & 7 (17.07) & 34 (82.93) & 0.445 \\
\hline Female & $6(11.54)$ & $46(88.46)$ & \\
\hline Age Median (IQR) & $25(24-28)$ & $28(22-32)$ & 0.257 \\
\hline \multicolumn{4}{|l|}{ Sign } \\
\hline IWL & 6 (13.04) & $40(86.96)$ & 0.812 \\
\hline $\mathrm{RR}$ & $5(17.86)$ & $23(82.14)$ & \\
\hline DR & 1 (11.11) & $8(89.89)$ & \\
\hline DC & $1(25.00)$ & $3(75.00)$ & \\
\hline NC & $0(0.00)$ & $6(100.00$ & \\
\hline \multicolumn{4}{|l|}{ СВСТ } \\
\hline No & $5(13.16)$ & $33(86.84)$ & 0.850 \\
\hline Yes & 8 (14.55) & $47(85.45)$ & \\
\hline \multicolumn{4}{|c|}{ Winters Classification } \\
\hline MA & $4(10.26)$ & 35 (89.74) & 0.480 \\
\hline v & 4 (13.33) & $26(86.67)$ & \\
\hline H & $5(20.83)$ & $19(79.17)$ & \\
\hline \multicolumn{4}{|l|}{ Pell Gregory } \\
\hline $1 \mathrm{~A}$ & $2(7.69)$ & 24 (92.31) & ${ }^{*} 0.036$ \\
\hline $2 \mathrm{~A}$ & $3(8.82)$ & $31(91.18)$ & \\
\hline 1B & $2(11.76)$ & $15(88.24)$ & \\
\hline 2B & $3(27.27)$ & 8 (72.73) & \\
\hline $2 \mathrm{C}$ & 2 (66.67) & 1 (33.33) & \\
\hline $3 \mathrm{~A}$ & $1(50.00)$ & $1(50.00)$ & \\
\hline \multicolumn{4}{|l|}{ Tooth } \\
\hline Right Side & $6(13.33)$ & 39 (86.67) & \\
\hline Left Side & $7(14.58)$ & 41 (85.42) & \\
\hline \multicolumn{4}{|l|}{ Work Experience } \\
\hline $5-15$ years & $11(16.92)$ & 54 (83.08) & 0.180 \\
\hline $15+$ & $2(7.14)$ & $26(92.86)$ & \\
\hline \multicolumn{4}{|l|}{ Surgical Procedure } \\
\hline Extraction & $0(0.00)$ & $9(100.00)$ & \\
\hline FE & $0(0.00)$ & $28(100.00)$ & \\
\hline FBE & $0(0.00)$ & $2(100.00)$ & ${ }^{*} 0.007$ \\
\hline FBD & $13(24.07)$ & $41(75.93)$ & \\
\hline \multicolumn{4}{|l|}{ Nerve Exposure } \\
\hline No & $10(11.49)$ & 77 (88.51) & ${ }^{*} 0.034$ \\
\hline Yes & $3(50.00)$ & $3(50.00)$ & \\
\hline
\end{tabular}

In the current study, transient injury occurred in $13.98 \%$ of cases and reduced to $1 \%$ after one month. Since the resolution of neurosensory disturbances occurred within four weeks after the procedure, neuropraxia was the most likely cause of transient sensory disturbance in this study.

Most studies consider diversion of the nerve canal and darkening of the roots of teeth as being significantly associated with an IAN injury. ${ }^{1-2,14}$ Other associated factors such as the interruption of the white line ${ }^{2,5}$ and narrowing of the canal ${ }^{16}$ show a close association with an IAN injury. In this study, none of these panoramic signs were associated with an IAN injury. However, the results of this study are skewed since most patients had an interruption of the white line and radiolucency of the roots.

\begin{tabular}{|c|c|c|c|c|}
\hline \multirow[t]{2}{*}{ Factors } & p-value & $\begin{array}{l}\text { Bivariate } \\
\text { Logistic } \\
\text { model }\end{array}$ & p-value & $\begin{array}{l}\text { Multivariate } \\
\text { logistic } \\
\text { model }\end{array}$ \\
\hline & & OR \& $95 \% \mathrm{Cl}$ & & OR \& $95 \% \mathrm{Cl}$ \\
\hline \multicolumn{5}{|l|}{ Gender } \\
\hline Male & & 1 & & \\
\hline Female & 0.447 & $0.63(0.19-2.06)$ & & \\
\hline Age Median (IQR) & 0.204 & $0.93(0.84-1.04)$ & & \\
\hline \multicolumn{5}{|l|}{ Sign } \\
\hline IWL & & 1 & & \\
\hline RR & 0.574 & $1.45(0.40-5.28)$ & & \\
\hline DR & 0.874 & $0.83(0.09-7.89)$ & & \\
\hline DC & 0.518 & $2.22(0.20-25.00)$ & & \\
\hline NC & & 1 & & \\
\hline \multicolumn{5}{|l|}{ СВСТ } \\
\hline No & & 1 & & \\
\hline Yes & 0.850 & $1.12(0.34-3.74)$ & & \\
\hline \multicolumn{5}{|l|}{$\begin{array}{l}\text { Winters } \\
\text { Classification }\end{array}$} \\
\hline MA & & 1 & & \\
\hline v & 0.693 & $1.35(0.31-5.89)$ & & \\
\hline H & 0.252 & $2.30(0.55-9.61)$ & & \\
\hline \multicolumn{5}{|l|}{ Pell Gregory } \\
\hline $1 \mathrm{~A}$ & & 1 & & 1 \\
\hline $2 A$ & 0.875 & $1.16(0.18-7.51)$ & 0.762 & $0.73(0.10-5.44)$ \\
\hline $1 B$ & 0.655 & $1.6(0.20-12.60)$ & 0.994 & $0.99(0.09-10.39)$ \\
\hline $2 B$ & 0.133 & $4.5(0.63-31.95)$ & 0.380 & $2.67(0.30-23.83)$ \\
\hline $2 \mathrm{C}$ & ${ }^{*} 0.026$ & $24(1.46-394)$ & ${ }^{\star} 0.022$ & $\begin{array}{l}40.41 \\
(1.71-951.85)\end{array}$ \\
\hline $3 \mathrm{~A}$ & 0.119 & $12(0.53-273)$ & 0.235 & $\begin{array}{l}180.15 \\
(0.03-953178.2)\end{array}$ \\
\hline \multicolumn{5}{|l|}{ Tooth } \\
\hline Right Side & & 1 & & \\
\hline Left Side & 0.862 & $1.11(0.34-3.59)$ & & \\
\hline \multicolumn{5}{|l|}{$\begin{array}{l}\text { Work } \\
\text { Experience }\end{array}$} \\
\hline $5-15$ years & 0.226 & $2.65(0.55-12.83)$ & & \\
\hline $15+$ & & 1 & & \\
\hline \multicolumn{5}{|l|}{$\begin{array}{l}\text { Nerve } \\
\text { Exposure }\end{array}$} \\
\hline No & & 1 & 1 & \\
\hline Yes & ${ }^{*} 0.021$ & $\begin{array}{l}7.7 \\
(1.36-43.46)\end{array}$ & ${ }^{\star} 0.008$ & $\begin{array}{l}17.30 \\
(2.10-142.50)\end{array}$ \\
\hline \multicolumn{5}{|c|}{${ }^{*} p>0.05$} \\
\hline \multicolumn{5}{|l|}{ Acronyms } \\
\hline $\begin{array}{l}\mathrm{IQR}=\text { interquan } \\
\mathrm{IWL}=\text { Interrupti }\end{array}$ & $\begin{array}{l}\text { tile range } \\
\text { on of white }\end{array}$ & & & \\
\hline
\end{tabular}

Further studies are needed to investigate the infrequent radiographic signs. Few studies have reported an association between the depth of an impacted tooth and an IAN injury. ${ }^{8,12,15}$ This study showed a statistically significant association between depth of impaction and IAN injury, probably because in deeper vertical impactions part of the tooth structure is below the level of the mandibular canal or the whole tooth may be lying along the length of the canal in horizontal impactions.

This study also found a significant association between nerve exposure and an IAN injury, which is in accord with the findings described in other reports..$^{5,10,13}$ However, according to Ghaeminia et al. ${ }^{1}$ there is no correlation between nerve exposure and sensory 
nerve impairment. Neurological disturbances in patients with nerve exposure are likely to be caused by nerve compression by the tooth or fragment of bone that was covering it and the nerve stretching that occurs when dissecting it out from overlying structures.

The study also showed that a surgical procedure that involves raising of the mucoperiosteal flap, bone removal, and sectioning of the tooth (FBD) is more likely to predispose patients to an IAN injury.

The association between FBD and IAN injury was statistically significant, with $p<0.05$. This finding is in agreement with the findings of a study by Blondeau and Daniel, 8 which also found that ostectomy and odontectomy (sectioning of the impacted tooth) were strongly associated with an IAN deficit.

A study by Hasengwa et al. ${ }^{5}$ also found that ostectomy was associated with neurosensory disturbances. It is not surprising that ostectomy and odontectomy are associated with neurological deficits since these procedures are performed in deep impactions.

Some studies reported an association between the experience of the surgeon and an IAN injury. ${ }^{8,13}$ On this point, our study is in agreement with a study by Hasengwa et al. ${ }^{5}$ which also found no association between experience and IAN injury. The difference between this study and a report by Cheung et al. ${ }^{13}$ is that in this series, specialists were removing deeper impactions that had a higher risk of an IAN injury.

\section{CONCLUSION}

The results of this study indicate that the use of information gleaned through a CBCT does not reduce the incidence of nerve injury during surgical removal of L3Ms. An extensive procedure involving removal of bone, odontectomy and manipulation of anatomical structures at varying depths of the tooth impaction (PGC 2B, 2C, and 3A) will largely influence the occurrence of an IAN injury during surgical extraction of L3Ms.

The significance of this finding is that the surgical procedure predisposes the patients to the risk of nerve injury, and the patients should always be informed of this risk. However, the outcome of this study needs to be confirmed with larger sample sizes that may include many cases of impactions at deep depths, where the surgical procedure is extensive and exposure of the nerve is likely to occur.

Conflict of interest: We have no conflicts of interest to declare.

Funding: The work was supported by the Department of Maxillofacial and Oral Surgery of the University of Witwatersrand.

Ethical approval: Data collection and the methods used in present study were approved by the Human Research Ethics Committee of the University of the Witwatersrand (M130915).
Informed consent: Informed consent was obtained from all volunteers.

\section{References}

1. Ghaeminia H, Meijer GJ, Soehardi A, Borstlap WA, Mulder J, Vlijmen OJ, Bergé SJ, Maal TJ. The use of Cone beam CBCT for the removal of wisdom teeth changes the surgical approach compared with panoramic study. Int. J Oral Maxillofac Surg. 2011; 40: 834-9.

2. Rood JP, Shehab BA. The radiological prediction of inferior alveolar nerve injury during third molar surgery. $\mathrm{Br} \mathrm{J}$ Oral Maxillofac Surg. 1990; 28:20-5.

3. Blaeserv BF, August MA, Donoff RB, Kaban LB, Dodson TB. Panoramic radiographic risk factors for inferior alveolar nerve injury after third molar extraction. J Oral Maxillofac Sur. 2003; 61:417-21.

4. Umar G, Obisesan O, Bryant C, Rood JP. Elimination of permanent injuries to the inferior alveolar nerve following surgical intervention of the "high risk" third molar. $\mathrm{Br} \mathrm{J}$ Oral Maxillofacial. 2013; 51:353-7.

5. Hasengwa S, Shigeta RT, Akashi M, Imai $Y$, Kakei $Y$, Shibuya $Y$, Komori T. Risk factors associated with inferior alveolar nerve injury after extraction of the mandibular third molar - a comparative study of preoperative images by panoramic radiography and computed tomography. Int $\mathrm{J}$. Oral Maxillofac. Surg. 2013; 42:843-51.

6. Sanmartí-Garcia G1, Valmaseda-Castellón E, Gay-Escoda C. Does computed tomography prevent inferior alveolar nerve injuries caused by lower third molar removal? J Oral Maxillofac Surg. 2012; 70:5-11.

7. Gupta J, Ali PS. Cone beam computed tomography in oral implants. Natl J Maxillofac Surg.2013; 4:2-6.

8. Blondeau F, Daniel NG. Extraction of impacted mandibular third molars: Post-operative complications and risk factors. J Can Dent Assoc.2007;73:325-8.

9. Leung YY, Cheung LK. Safety of coronectomy versus excision of wisdom teeth: A randomized controlled trial. Oral Surg Oral Med Oral Path Oral Radiol Endodontics. 2009; 108:821-7.

10. Long $H$, Zhou $Y$, Liao L, Pyakurel, Wang $Y$, Lai $W$. Coronoidectomy vs total removal for third molar extraction: A systemic review. J Dent Res.2012; 91:659- 65.

11. Ueda M, Nakamori K, Shiratori et al. Clinical significance of computed tomographic assessment and anatomic features of the inferior alveolar canal as risk factors for injury of the inferior alveolar nerve at third molar surgery. J. Oral Maxillofac Surg. 2012; 70:514-20.

12. Ghaeminia H, Meijer GJ, Soehardi A, BorstlapWA, Mulder J, Vlijmen OJ, et al. The use of cone beam CT for the removal of wisdom teeth changes the surgical approach compared with panoramic radiography: a pilot study. Int J Oral Maxillofac Surg. 2011; 40:834-9.

13. Cheung LK, Leung YY, Chow LK, Wong MCM, Chan EKK, Fok $\mathrm{YH}$. Incidence of neurosensory injury and recovery after lower third molar surgery: a prospective clinical study of 4338 cases. Int. J. Oral Maxillofac Surg. 2010; 39:320-6.

14. Umar G, Bryant C, Obisesan O, Rood JP. Correlation of the radiographical predictive factors of inferior alveolar nerve injury with cone beam computated tomography findings. Oral Surgery.2010; 3: 72-82.

15. Leung YY, Cheung LK. Risk factors for neurosensory deficits in lower third molar surgery: a literature review of prospective studies. Int. Oral Maxillofac Surg. 2011; 40:1-10.

16. Eyrich G, Seifert B, Mathews F, Matthiessen U, Heusser CK, Kruse AL, Obwegeser JA, Lubbers H. 3-dimensional imaging for lower third molars: is there any implication for surgical removal? J Oral Maxillofac Surg. 2011; 69:1867-72. 